Territorios 35 / Bogotá, 2016, pp. 59-80

ISSN: 0123-8418

ISSNe: 2215-7484

La fase actual del capitalismo y la urbanización en América Latina (II)

\title{
Marginalidad, precariado y marginalidad avanzada: definiciones teóricas y realidades empíricas desde distintos contextos socio- espaciales en la ciudad de México*
}

\section{Marginality, Precariat and Advanced Marginality: Theoretical Definitions and Empirical Realities from Different Socio-spatial Contexts in Mexico City \\ Marginalidade, precariado e marginalidade avançada: definições teóricas e realidades empiricas desde distintos contextos socio-espaciais na Cidade do México}

\section{Ángela Giglia*}

Recibido: 8 de febrero de 2016

Aprobado: 30 de marzo de 2016

Doi: dx.doi.org/10.12804/territ35.2016.03

Para citar este artículo:

Giglia, A. (2016). Marginalidad, precariado y marginalidad avanzada: definiciones teóricas y realidades empíricas desde distintos contextos socio-espaciales en la ciudad de México. Territorios, 35, 59-80. Doi: dx.doi. org/10.12804/territ35.2016.03

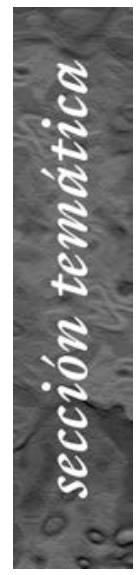

* Una versión preliminar de este texto ha sido preparada para el II Seminario Internacional de la Red Latinoamericana de Investigadores sobre Teoría Urbana, Medellin, Colombia, 18, 19y 20 de febrero de 2015, dedicada al tema La fase actual del capitalismo y la urbanización en América Latina.

* * Doctora en Ciencias Antropológicas y análisis de los cambios culturales por el Instituto Oriental de Nápoles y doctora en Antropología social y etnología por la EHESS de París. Actualmente profesora-investigadora en el Departamento de Antropología de la Universidad Autónoma Metropolitana - Iztapalapa, México. Correo electrónico:ag@xanum.uam.mx 
Palabras clave

marginalidad, precariado, pobreza urbana, movilidad, redes sociales, vecindario.

Keywords

Marginalization, Urban poverty, Mobility, Precariousness, Social networks, Neighborbood.

Palavras-chave marginalidade, precariado, pobreza urbana, mobilidade, redes sociais, vizinhança.

tersitarias 35

\section{RESUMEN}

En este texto propongo una reflexión acerca de los conceptos de marginalidad urbana y precariado a partir de una articulación entre datos empíricos y conceptos teóricos. Se discuten algunas definiciones teóricas y se vinculan con la realidad de trabajadores precarios que laboran sin recibir un salario en el sector de los servicios al consumo, denominados en México como propineros. Estos trabajadores representan una parte constitutiva del sistema económico y una presencia ineludible en el mercado laboral metropolitano, aunque difícil de cuantificar a partir de fuentes oficiales. Para estudiar su condición de precariedad con respecto al trabajo, esta debe ser examinada en un contexto más amplio, considerando en particular ciertos elementos socio-espaciales entre los cuales destacan sus lazos familiares y barriales, sus redes de apoyo y su ubicación en la metrópoli.

\section{ABSTRACT}

In this paper I propose a reflection on the concepts of urban marginality and Precariat starting from an articulation between empirical data and theoretical concepts. Some theoretical definitions are discussed and linked to the reality of precarious workers who work without any pay in the sector of consumer services known in Mexico as propineros. These workers represent a constituent part of the economic system and an inescapable presence in the metropolitan labor market, although difficult to quantify from official sources. To study the condition of precariousness in regard to work, it must be examined in a broader context, particularly considering certain socio-spatial elements such as family and neighborhood ties, support networks and their location in the metropolis.

\section{RESUMO}

Neste texto proponho uma reflexão acerca dos conceitos de marginalidade urbana e precariado a partir de uma articulação entre dados empíricos e conceitos teóricos. Discutem-se algumas definições teóricas e vinculam-se com a realidade de trabalhadores precários que trabalham sem receber um salário no setor dos serviços ao consumo, denominados no México como propineros. Estes trabalhadores representam uma parte constitutiva do sistema económico e uma presença ineludível no mercado laboral metropolitano, ainda que difícil de quantificar a partir de fontes oficiais. Para estudar a sua condição de precariedade com respeito ao trabalho, esta deve ser examinada em um contexto mais amplo, considerando em particular certos elementos socioespaciais entre os quais destacam os seus laços familiares e bairristas, as suas redes de apoio e a sua ubiquação na metrópole. 


\section{La marginalidad urbana y la ciudad de México en la actualidad}

Este texto propone una reflexión acerca del concepto de marginalidad urbana, cuyo auge en América Latina se remonta a los años sesenta y setenta del siglo pasado, y que ha vuelto a ser objeto de debate en tiempos más recientes ante las condiciones generadas por las crecientes desigualdades socioespaciales y la progresiva precarización y flexibilización de la relación con el trabajo. ¿Cómo ha cambiado la condición de marginalidad desde ese entonces? ¿Quiénes son hoy en día los marginados en las grandes ciudades de América Latina? ${ }^{1}$ En 1975 se publicó por primera vez un libro que desde entonces ha tenido gran difusión e impacto en las ciencias sociales en América Latina. Se trata de Cómo sobreviven los marginados, que la antropóloga de origen chileno Larissa Lomnitz escribió teniendo como interlocutores principales los habitantes de una colonia popular de la zona suroeste de la Ciudad de México, cuyo nombre ficticio es el de Cerrada del Cóndor. Sus habitantes eran predominantemente empleados de forma precaria como trabajadores manuales en el sector de la construcción y en el servicio doméstico. Como se recordará, el análisis de Lomnitz apuntaba a evidenciar la eficacia y la extensión de las redes de solidaridad entre los habitantes de la Cerrada, para responder la pregunta contenida en el título del libro. Así mismo, en el libro de Lomnitz se definía la condición de marginalidad a partir de la incertidumbre con respecto a la cantidad y predictibilidad de los ingresos. Cabe preguntarse, en un entorno socio-económico y socio-espacial profundamente distinto como es el actual, si las característica de la marginalidad propuestas por Lomnitz para describir a los trabajadores precarios urbanos, siguen siendo vigentes. Considero pertinente este tema de reflexión ya que recientemente ha habido un regreso de interés por el tema de la marginalidad y su definición. Me refiero a la propuesta que hace en su último libro Loic Wacquant, al presentarnos el concepto de marginalidad avanzada, el cual veremos en detalle algunas páginas más adelante. ¿Cuáles son las diferencias entre la definición de marginalidad propuesta por Lomnitz hace cuarenta años y la marginalidad avanzada de la actualidad? Y entre una definición y la otra, ¿cuáles cambios sociales han llevado en años más recientes a la difusión del concepto de precariado? ¿Se pueden usar estos conceptos como si fueran sinónimos, para hablar de los mismos actores sociales? ¿Acaso la condición de marginalidad es una característica propia de todos los trabajadores precarios? ¿O bien no puede darse por sentada una necesaria coincidencia entre la condición de precariedad laboral y la marginalidad urbana? ¿Cuáles elementos del contexto socioespacial son importantes para entender la condición actual de marginalidad urbana?

En el caso de la metrópoli de México es indispensable mencionar los siguientes fenómenos para caracterizar la situación actual. El primero se refiere al aumento de las desigualdades socio-espaciales, especialmente entre dos contextos urbanos,
${ }^{1}$ Una revisión de los autores que han trabajado sobre la condición de marginalidad y la exclusión de los pobres urbanos en América Latina excede por mucho los objetivos de este texto, el cual se limita unicamente a tres autores -Lomnitz, Standing y Wacquantcuyos aportes destacan entre otras cosas por haber tenido una amplia resonancia, más allá del ámbito empirico sobre el cual edifican su análisis. Sin ninguna pretensión de agotar la lista, importantes aportes sobre la marginalidad en América Latina han sido elaborados por Castel, R., Kessler, G., Merklen, D., \& Murard, N. (2013); De la Rocha, $M$. G. (2001); De la Rocha, $M$. G., Perlman, J., Safa, H., Jelin, E., Roberts, B. R., \& Ward, P. M. (2004); Eckstein (1999); Kaztman, R. (2001); Lewis, O. (1970); Nun,J. (2001); O'Donnell, G. A., \& Tokman, V. E. (1999); Saravi, G. (2006).

Además de los autores considerados en este texto, $y$ más allá del ámbito latinoamericano, sobre el tema de la marginalidad y la exclusión en ámbito urbano constituyen aportes fundamentales los textos de Bauman, Z. (2000); Bourdieu, P. (1999); Pangam, $S$. (2007), entre otros.

\section{territarias 35}


${ }^{2}$ Un reciente estudio de la UNAM advierte que, por la baja en el poder adquisitivo de los salarios actualmente más de 10 millones de mexicanos no pueden comprar los 40 alimentos que componen la canasta básica, porque su ingreso es inferior a los dos salarios minimos diarios. Como essabido el salario mínimo en el DF es de poco más de 67 pesos y el costo diario de la canasta básica es de alvededor de 184 pesos. El mismo estudio señala que de 1987 a la fecha la perdida en el poder adquisitivo de los mexicanos es de 77,9 por ciento. Mientras hace 27 años se podia adquirir la canasta con 4 horas de trabajo abora sería necesaria una jornada de 22 horas (Emir Olivares Alonso "Más de 10 millones sin poder para comprar alimentos básicos", en "Sociedad y Justicia” La Jornada 7 de mayo de 2014, p. 37)

${ }^{3}$ El comercio informalen los cruces viales es un fenómeno propiamente metropolitano ya que su oferta responde de manera muy precisa a las exigencias de la movilidad privada automotriz, adecuándose a las necesidades del automovilista en distintos momentos y lugares del día. Véase al respecto el estudio de Monnet, Giglia,

\section{territarias 35}

el de la llamada ciudad central y el de las periferias alejadas donde se encuentran básicamente tres tipos de contextos urbanos: los asentamientos de autoconstrucción menos consolidados, los conjuntos urbanos de interés social construido grosso modo en el periodo de 2000 a 2012 y los pueblos de origen colonial o prehispánicos con diversos grados de conexión con el territorio urbanizado. Los procesos de valorización urbana en la ciudad central, la expansión de las periferias y la falta de una política metropolitana de transporte colectivo han acrecentado las distancias físicas, sociales y económicas entre estas dos realidades urbanas (Coulomb, 2012; Duhau, 2008; Ziccardi, 2012). El segundo fenómeno lo constituye la exacerbada flexibilización de las relaciones laborales, debido a la reforma laboral, que ha legalizado la subcontratación, el trabajo por día y por horas, sin que esto signifique más oportunidades de empleo; la condición de desamparo ante sus empleadores que experimenta la mayoría de los trabajadores, debido a la falta de libertad sindical y de sindicatos efectivamente dedicados a la defensa de los intereses de sus agremiados. El tercer fenómeno consiste en la pérdida acelerada del poder de compra del salario, por efecto de una política de contención salarial para favorecer la competitividad de las empresas mexicanas en el mercado mundial, mediante una definición y control institucional del monto del salario mínimo, el cual ha llegado a ser el más bajo en el continente ${ }^{2}$ (Mora Salas, 2010; Bensusan, 2000; Bouzas, 2010). Un cuarto fenómeno es el peso creciente de la economía informal e ilegal, difícil de medir a partir de cifras oficiales, pero que se estima en alrededor del $23.7 \%$ del PIB (INEGI, 2016). La vitalidad de esta economía informal debe ser tomada en cuenta de manera cada vez más sistemática si se quiere entender cómo sobreviven los marginados en la actualidad. Se trata de una realidad económica profundamente entreverada con la economía oficial, que refleja la que Gustavo Lins Ribeiro define como "globalización desde abajo" (Alba, Lins Ribeiro \& Mathews, 2015), cuya abrumadora presencia se impone a simple vista en las calles de la metrópoli, donde el comercio informal representa un elemento recurrente y predecible del paisaje urbano ${ }^{3}$.

Las interacciones entre estos fenómenos dibujan un escenario con tintes cada vez más dramáticos en el cual han surgido figuras novedosas de trabajadores precarios, que hace pocos años hubieran sido impensables. Es el caso de los trabajadores subordinados que trabajan sin recibir salario alguno, reflejo de las condiciones de vulnerabilidad y desventaja ya mencionadas, en las cuales el derecho mismo a recibir un salario por el trabajo realizado ha sido puesto en entredicho. Especialmente en el sector terciario, nos encontramos con trabajadores cuya única fuente de ingresos son las propinas que reciben de los consumidores. Lo que debería ser un elemento imprescindible de la relación laboral, es decir la remuneración por el trabajo realizado, es obviada por el patrón y es transferida sobre el consumidor del servicio. A partir de exponer la situación de estos trabajadores, 
se evidencia un conjunto de condiciones que de manera conjunta contribuyen a delinear la condición de marginalidad urbana, no solo sus circunstancias laborales, sino sus redes de relaciones y las realidades de su ubicación en la metrópoli, especialmente el lugar donde residen y la distancia del lugar de trabajo ${ }^{4}$.

Presentaré en una primera parte los tres conceptos de marginalidad, precariado y marginalidad avanzada. Para después discutir cuáles aspectos de la definición de Lomnitz y cuáles aspectos de la marginalidad avanzada recientemente propuesta por Wacquant resultan pertinentes para dar cuenta de las condiciones de vida de un grupo de trabajadores propineros. A partir de un conjunto de entrevistas llevadas a cabo con estos trabajadores, me propongo evidenciar la manera como sus redes familiares y barriales y su lugar de residencia en distintos contextos urbanos en la metrópoli pueden modificar la visión que tienen sobre ellos mismos y su futuro. La idea de fondo es que la condición de marginalidad y de precariedad en la metrópoli tiene que ser analizada como el resultado de un conjunto de elementos, no únicamente laborales, sino también familiares y socio-espaciales, estos últimos especialmente relativos a la localización de la vivienda y su relación con el lugar de trabajo. Me propongo dar cuenta del papel de las redes de relaciones en la organización de su vida cotidiana, con el objetivo de desentrañar algunas de las nuevas facetas de la marginalidad urbana, articulándola por un lado con el trabajo precario y por el otro con la ubicación en distintos contextos socio-espaciales.

\section{Los conceptos de marginalidad, precariado y marginalidad avanzada}

A continuación expondré el concepto de marginalidad propuesto por Larissa Lomnitz, en su libro Cómo sobreviven los marginados para luego detenerme en el más reciente concepto de precariado, acuñado en Europa desde los años ochenta del siglo pasado y recientemente retomado y sistematizado en el libro publicado por Guy Standing (2011) (The precariat. The new dangerous class); y en el concepto de marginalidad avanzada propuesto por Löic Wacquant (2007) en su libro Los condenados de la ciudad.

El tema de las condiciones de vida de los pobres urbanos y de su relación con el mercado de trabajo, formal e informal, ha sido objeto de estudios ya clásicos en la antropología y la sociología de las ciudades latinoamericanas. En los años setenta del siglo pasado, en su libro, Lomnitz (1975) define la condición de marginalidad a partir de la "inseguridad económica", es decir el hecho de no poder contar con un ingreso estable, seguro y predecible. En sus palabras "hay maestros de escuela que ganan menos de un capataz en una construcción y sin embargo no son marginados como este". Para Lomnitz (1975) los marginados "enfrentan el problema de la supervivencia con los solos recursos de su destreza, su astucia y su solidaridad social" (p. 96). En su análisis, las redes de apoyo juegan un
\& Capron (2007) sobre la oferta comercial informal en distintos cruces viales en la ciudad de México.

${ }^{4}$ La investigación en la que se basa este texto forma parte del proyecto Habitar la ciudad informal: condiciones de precariedad y prácticas urbanas en los espacios de la vivienda y el trabajo, aprobado por el Consejo D $i$ visional de la UAM Iztapalapa desde 2012 a la fecha.

territarias 35 
papel fundamental en garantizar no solo su supervivencia, sino también sus particulares formas de integración en la sociedad urbana. Las redes que se tejen en el ámbito del espacio local de la barriada, revisten una importancia fundamental. Desde el enfoque localizado que es propio de un estudio antropológico, Lomnitz reconstruye el entramado de redes de intercambio basadas en el espacio de la barriada, las cuales en definitiva definen a este contexto espacial desde su fundación, además de dar cuenta de su funcionamiento como comunidad local. Las 45 redes de intercambio que Lomnitz identifica constituyen:

[...] el elemento de estructura social más significativo en la barriada, ya que permiten explicar el proceso de migración, el patrón de asentamiento en la ciudad, los frecuentes movimientos y cambios de domicilio dentro del radio urbano, el patrón ocupacional de los pobladores, y sobre todo el hecho incontrovertible de su supervivencia económica (Lomnitz, 1975, p. 219).

En este entramado de redes de distinto tipo, desde las familiares hasta las de compadrazgo y el cuatismo, la confianza resulta ser el "cemento que une a los integrantes de la red, pues describe la cercanía psicosocial capaz de reducir las barreras al intercambio y de promover las expectativas de reciprocidad" (Lomnitz, 1975, p. 219). Los marginados de Cerrada del Condor sobreviven porque están dispuestos a intercambiar y a apoyarse en casi todo, estrechando lazos de ayuda mutua. Su condición esencial es su "falta de vinculación y de integración al sistema económico urbano industrial" (Lomnitz, 1975, p. 219) la cual es aminorada y en parte superada gracias a las redes de intercambio.

Desde los años setenta, y sobre todo en los ochenta, empieza a ser usado en algunos países europeos el concepto de precariado, especialmente desde los años setenta en Italia, para denotar al conjunto de los trabajadores del sector de la educación pública desprovistos de una plaza estable, suplentes y otros tipos de trabajadores temporales, que debían (y deben) atenerse a las mismas exigencias y condiciones de trabajo, pero sin las prerrogativas de una relación laboral estable por tiempo indeterminado. El término ha sido utilizado sucesivamente en Europa por muchos autores (Castel, 2007; Corsani \& Lazzarato, 2008), aunque no siempre con un idéntico significado. Se puede decir que el concepto de precariado posee un alcance variable, dependiendo de si se aplica exclusivamente al ámbito de los fenómenos de precarización con respecto al modelo del trabajo asalariado, o también al ámbito de las diferentes figuras del trabajo independiente y no subordinado, y en este segundo caso tiene semejanzas importantes con el concepto de trabajo informal. El elemento que unifica los distintos usos del término tiene que ver con un común horizonte de reflexión, que se refiere a la trasformación de la llamada economía fordista, donde prevalecían condiciones de empleo asalariado asociadas a prestaciones laborales, seguridad social y estabilidad laboral (que se concretaban con el empleo 
virtualmente de por vida en un mismo lugar de trabajo y la sucesiva jubilación con una pensión también de por vida) en el marco de una forma de gobierno que se conoce como estado de bienestar. Estas condiciones prevalecieron en los países europeos hasta los años setenta del siglo pasado. A partir de esa época, a raíz de procesos globales de reestructuración de la economía, el trabajo asalariado ha ido perdiendo muchas de sus características anteriores y se ha flexibilizado y pulverizado con la aparición de figuras de contratos temporales, de medio tiempo, de aprendizaje, etc., figuras que tienen en común el abaratar los costos en prestaciones y seguridad social asociados a la antigua relación del trabajo asalariado estable. Es en este contexto que se vuelve de uso común el término precariado ${ }^{5}$.

Recientemente el libro de Guy Standing, The precariat. The new dangerous class, publicado en 2011, atrajo con fuerza la atención sobre este amplísimo sector de trabajadores, entre otras cosas por la tesis de su supuesta peligrosidad social, la cual derivaría de una actitud individualista y competitiva, debido a su miedo y desconfianza con respecto al futuro, resultado de su exacerbada vulnerabilidad, de la heterogeneidad de su condición, que según este autor los volvería fácil presa de movimientos populistas y autoritarios. El concepto de precariado propuesto por Standing designa el conjunto de los trabajadores que no disfrutan de ese conjunto de seguridades "que los partidos socialdemócratas o laboristas y los sindicatos pretendían imponer tras la Segunda Guerra Mundial como progra- ma de 'ciudadanía industrial' para la clase obrera y el proletariado" (Standing, 2013, p. 30) como son la seguridad del mercado laboral, (es decir "oportunidades para obtener un ingreso decente"), la seguridad en el empleo (como protección en la relación con el patrón en caso de despido arbitrario, etc.), la seguridad en el puesto de trabajo (como facilidades para "mantenerse en un nicho de empleo"), la seguridad en el trabajo (como seguridad física contra accidentes y enfermedades), y finalmente la seguridad en la reproducción de las habilidades, en los ingresos y en la representación (libertad sindical y derecho de huelga, entre otros) (Standing, 2013, p. 31). El conjunto de estas condiciones de seguridad corresponde a lo que la Organización Internacional del Trabajo define como "trabajo decente", que en América Latina se conoce como "trabajo digno", y que resulta de estas componentes: el empleo, la protección social, los derechos de los trabajadores y el dialogo social. No cabe duda, con base en estas definiciones, que los trabajadores propineros objeto de nuestra investigación forman parte del precariado.

El término precariado ha sido usado de manera tangencial también por Loic Wacquant, quien retoma la idea de marginalidad en una clave interesante desde el punto de vista que nos ocupa en este texto. Este autor propone lo que denomina como marginalidad avanzada en su libro Los condenados de la ciudad (2007 [primera edición: 2006]). Este autor se plantea no separar el ámbito laboral del ámbito espacial, sino que considera al mismo tiempo
${ }^{5}$ La palabra viene del latín precarium que era en origen una concesión de tierras que se obtenia después de una plegaria (prece, en latín) dirigida a un señor terrateniente, el cual, al otorgar el uso de la tierra y su protección al campesino, al mismo tiempo se reservaba el derecho de quitárselas - tanto la tierra como su protección-en cualquier momento. Es un origen etimológico muy elocuente para definir una relación laboral en la cual el trabajador no tiene ninguna certeza con respecto a la duración y a las condiciones de su trabajo, y donde en cambio prevalecen la incertidumbre, la vulnerabilidad y la subordinación con respecto a otros, quienes determinan de manera a menudo arbitraria e impredecible, las condiciones de trabajo, los tiempos de su realización y la duración de la relación laboral.

territarias 35 
${ }^{6}$ A este respecto, vale la pena recordar como ya desde los años setenta del siglo pasado, destacados autores latinoamericanos pusieron el acento sobre la articulación intrínseca de la condición de marginalidad con el sistema económico de esa época, subrayando que no se trataba de un fenómeno residual o pasajero, sino de un fenómeno funcional a la reproducción del sistema mismo, considerando a la masa marginal como una "palanca o condición de existencia del sistema de producción” (Nun, 1969; Quijano, 1988).

\section{territarias 35}

la posición de los sujetos con respecto al mercado del trabajo y su posición en el contexto socio-espacial del cual provienen. Es oportuno detenernos sobre su definición y preguntarnos si es aplicable al contexto de la metrópoli de México y en general a un contexto diferente con respecto al ámbito desde el cual este autor elabora su propuesta, es decir las periferias de vivienda de interés social de las ciudades francesas y el gueto negro de las ciudades norteamericanas, especialmente de Chicago. Wacquant (2007) considera a la marginalidad actual como un conjunto de:

[...] nuevas formas de clausura excluyente, que se traducen en una expulsión al margen del espacio social y físico, que han surgido - o se han intensificado- en las metrópolis postfordistas, no bajo el efecto de la inadaptación o el estancamiento económico, sino, muy por el contrario, como consecuencia de la mutación de los sectores más avanzados de las sociedades y las economías occidentales (pp. 268-269).

Para Wacquant (2007) estas formas de marginalidad no están destinadas a desaparecer ni a ser reabsorbidas por el mercado o por la acción del estado, sino que "se dibujan delante nuestro: están inscriptas en el devenir de las sociedades contemporáneas" (p. 269). Como ya ha sido destacado por importantes autores latinoamericanos, también Wacquant considera que la marginalidad actual es una condición estructural de la sociedad contemporánea ${ }^{6}$.
Wacquant propone un conjunto de seis propiedades distintivas de la nueva marginalidad, recordando que este concepto es un tipo ideal, es decir una "abstracción socio histórica fundada sobre las manifestaciones concretas de un fenómeno" (Wacquant, 2007, p. 270) y que su elaboración se ofrece para ver si sirve o no a la formulación de hipótesis para el análisis. Algunas propiedades distintivas son más de tipo socio-económico y se refieren a la inseguridad intrínseca a la condición de asalariado debido a la flexibilización y fragmentación de este tipo de empleo; a la "desconexión con respecto de las tendencias macroeconómicas" (Wacquant, 2007, p. 273), que hacen que la marginalidad se haya vuelto independiente de los ciclos de expansión o contracción de la economía; y a la "fragmentación social y estallido simbólico" (Wacquant, 2007, p. 273) refiriéndose al carácter por definición fragmentario e inacabado del precariado, imposibilitado para pensarse colectivamente en el presente y en el futuro". Otras propiedades son más de tipo socio-espacial. Una se refiere a la "fijación y estigmatización territoriales", que indica la tendencia de las poblaciones marginadas a "la concentración en territorios aislados y claramente circunscritos" de los cuales emana un estigma definible como “infamia territorial” (Wacquant, 2007, pp. 274-275), que acrecienta las desventajas de sus habitantes por el solo hecho de habitar allí y no en otro lado. Otra se refiere a la "alienación espacial y la disolución del $l u$ gar", entendidos como "la pérdida de un marco humanizado, culturalmente familiar 
y socialmente tamizado, con el que se identifiquen las poblaciones urbanas marginadas" (Wacquant, 2007, pp. 278-279) que estarían ya desprovistas de vínculos socioespaciales de referencia y solidos. Otra característica del mismo tenor tiene que ver con lo que Wacquant propone denominar como "la pérdida de un país interno (hinterland)" (Wacquant, 2007, p. 281) en los cuales los marginados puedan refugiarse o replegarse en los momentos más agudos de las crisis, tales como los barrios o los pueblos de procedencia o las zonas de inmigración, lugares que sí eran efectivos como refugios en la épocas anteriores a las reestructuración de la economía.

En lo que sigue vincularé estas tesis sobre la marginalidad, el precariado y la marginalidad avanzada con la realidad que protagonizan unos trabajadores sin salario en la ciudad de México. En particular me focalizaré aquí sobre los rasgos relativos a su condición socio-espacial y a la presencia o ausencia de redes de apoyo en sus vidas. La estigmatización territorial, la pérdida del lugary de una comunidad refugio (binterland) ¿pueden ser considerados como atributos que definen la condición de estos trabajadores precarios en la ciudad de México? ¿Cuán vigente es la tesis de Lomnitz sobre la importancia esencial de las redes de apoyo para la supervivencia y la inserción en el mundo del trabajo y en la ciudad? La representación de los marginados actuales como un precariado atomizado, asustado y enojado ¿se adapta al caso de los trabajadores mexicanos que hemos conocido? ¿Cómo incide la ubicación en el espacio metropolitano dentro de la condición de precariedad y marginalidad? ${ }^{7}$

\section{Marginados y precarios: propineros en la ciudad de México y sus experiencias}

En una gran metrópoli como la ciudad de México, las condiciones de vida de los trabajadores precarios tienen que ver no solo con los aspectos laborales o con las características y las estructuras de las políticas de apoyo institucional para los sectores de menores recursos; sino con factores socioespaciales, sobre algunos de los cuales nos detendremos aquí de manera especial, es decir las redes informales de apoyo, especialmente laborales, familiares y barriales, en el seno de las cuales los sujetos pueden encontrar la manera para subsistir y salir adelante; y su ubicación en el espacio de la metrópoli y las diversas oportunidades vinculadas con esta ubicación espacial, empezando por la conexión y la distancia de su lugar de trabajo.

Los trabajadores de los cuales trataremos ahora se desempeñan como despachadores de gasolina y sus funciones consisten en facilitar al consumidor la tarea de cargar gasolina en su auto, accionando una maquina despachadora computarizada. Como otros trabajadores del sector de los servicios al consumidor, ocupan el último eslabón de la fase de circulación de las mercancías, como diría Marx, siendo justamente su tarea la de entregar la mercancía en manos del consumidor. A su vez ellos se encuentran puestos metafóricamente en las manos del
7 Para un análisis de los diferentes contextos socioespaciales en la metrópoli de México remito a Dubau \& Giglia (2008). 
${ }^{8}$ La remuneración mediante propinas es cada vez más común en la ciudad de México y en otras grandes ciudades globales, principalmente en el sector de los servicios al consumidor: los empacadores (las personas que ayudan a llenar las bolsas del supermercado), los acomodadores de coches, los meseros en las grandes cadenas restauranteras, $\mathrm{e}$ incluso los vendedores de coches $y$ de seguros, no reciben un salario, sino solo propinas o un magro porcentaje de las ventas que realizan (Peña ¿ Castillo, 2014; Giglia, 2015).

${ }^{9}$ En México es casi imposible la existencia de sindicatos independientes que emanen de la libre asociación de los trabajadores. Prevalecen sindicatos dotados de una estructura vertical y autoritaria, surgidos casi todos en la época posrevolucionaria e inspirados directamente en la organización de los trabajadores forjada por el régimen fascista en Italia (Robles, 2007), se encuentran respaldados por la ley vigente, la cual permite un tipo de contratación en defensa de los intereses patronales, como el caso de los llamados"contratos colectivos de protección patronal" (ССРP), de cuya existencia los trabajadores no están si-

territarios 35 consumidor ya que solo de él depende su sustento mediante la propina, una erogación en dinero que en México no es obligatoria. En efecto, a cambio de poner la gasolina en el tanque del automóvil, los gasolineros reciben una propina de monto variable en relación con una serie de elementos que están fuera de su control. Existe de hecho la posibilidad de no recibir la propina, y esto por las razonen más diversas, desde la ausencia de monedas fraccionarias, el estado de ánimo del cliente en ese momento, hasta las opiniones según las cuales el trabajador no la necesita o no se la merece. Las condiciones de existencia de los propineros expresan de manera exacerbada esa incertidumbre con respecto a los ingresos de la que hablaba Larisa Lomnitz para definir la condición de los marginados. Además, los propineros actuales desempeñan un papel importante al interior del sistema económico —en el cual los servicios al consumidor son cada vez más comunes y diferenciados-y una presencia ineludible en el mercado laboral metropolitano ${ }^{8}$, en coincidencia con la tesis de la marginalidad avanzada según Wacquant, por la cual su condición no es transitoria, sino estable y destinada a prolongarse a futuro. En relación con esto, hay que subrayar que los gasolineros trabajan por grandes empresas formalmente establecidas, lo cual no impide que sus condiciones de trabajo sean extremadamente precarias y vulnerables, con lo cual la distinción entre sector formal y sector informal se desdibuja, en un contexto de reglamentaciones laborales que niegan la organización autónoma de los trabajadores 9 .
Los datos que presento a continuación se refieren a trabajadores gasolineros que residen en contextos sociales diferentes, unos pocos en barrios populares situados en el área más céntrica de la ciudad y la mayoría de ellos en colonia de autoconstrucción, en conjuntos urbanos o en pueblos semirrurales situados en las extremas periferias de la metrópoli especialmente en el área oriental donde se concentra la mayoría de la población de escasos ingresos del área metropolitana. Los datos han sido recabados a partir de un conjunto de entrevistas grupales, realizadas entre septiembre 2011 y mayo 2013 a más de 30 hombres y mujeres que trabajan en diversas gasolineras en la ciudad de México; y de la etnografía de diversas situaciones colectivas como asambleas, convivios y marchas de protesta, a las cuales he tenido la oportunidad de asistir practicando una observación semiparticipante (Guber, 2004), desde 2011 hasta 2014. En las entrevistas hablan colectivamente sobre sus condiciones laborales y como han cambiado en los últimos años, la organización de la vida cotidiana para sobrellevar los turnos de trabajo, y la movilidad diaria entre la casa y el trabajo, entre otros temas. Las entrevistas se realizaron con grupos de cuatro a seis trabajadores y trabajadoras, en dos etapas o sesiones, una primera etapa sobre los temas de la organización del trabajo y una segunda sesión sobre la organización de la vida cotidiana y la movilidad. Puede contactarme con ellos y obtener su disponibilidad para hablar de su condición gracias a la intermediación de una organización civil empeñada en 
obtener una mejora de sus condiciones laborales. Esto hizo que el ambiente de estas reuniones fuera propicio para la apertura y el diálogo entorno a su condición laboral y para la comparación y reflexión colectiva sobre las experiencias comunes y las similitudes y diferencias en la condición de cada uno. Con muchos de estos trabajadores se han mantenido relaciones que perduran hasta el día de hoy y que es posible reanudar para futuras profundizaciones ${ }^{10}$.

La mayoría de los gasolineros está obligado a pagar un derecho de piso para poder empezar a trabajar en la estación de gasolina, generalmente en actividades en las cuales las propinas son más inciertas, como por ejemplo el lavado de vidrios o de las llantas de los autos. La asignación a una maquina despachadora implica manejar un conjunto de conocimientos relativo al funcionamiento de esta y a las modalidades de cobro y pago, habilidades que son aprendidas mediantes entrenamientos cortos de pocas horas, para ejercer tareas que implican asumir grandes responsabilidades, especialmente en relación con el flujo de dinero que llega a las estaciones mediante las tarjetas de débito o crédito y en buena medida en efectivo. El trabajador está en una posición de subordinación no solo en relación con otros despachadores que ocupan un rango superior, sino sobre todo con respecto a los gerentes de las gasolineras, y los dueños de estas. Es imprescindible llegar puntuales y respetar horarios (por lo general tres turnos de ocho horas cada uno, ya que las mayoría de las gasolineras dan servicio las 24 horas); vestir un uniforme y a veces un gorro con el logo de la empresa; acatar un conjunto de normas precisas en la relación con el cliente y con los demás trabajadores. La rigidez de esta organización del trabajo coexiste con la arbitrariedad de los gerentes hacia los despachadores, que se manifiesta por ejemplo con cambios de turnos o descansos improvisos e inmotivados. Para el dueño de la gasolinera, los despachadores no son dependientes de los cuales tiene que hacerse responsable, sino personas a las que les hace el favor de permitirles trabajar en la planta despachadora. Su mano de obra es gratis y además puede ser usada sin costo alguno en muchas otras labores. En efecto, los despachadores suelen realizar otras tareas, como recibir las autoclaves y descargarlas en las cisternas; hacer cuentas, pagos y depósitos en el banco de las ganancias diarias o semanales; darle mantenimiento a toda la estación: pintar, barrer, hacer pequeñas reparaciones, etc. En algunos casos los gerentes se sirven de ellos como factótums, para las tareas que sean necesarias, como choferes, lavadores de coches, encargados de diversos mandados, vendedores de aditivos y otros productos y hasta para pasear a sus perros. Además, la mayoría de las veces trabajan sin tener seguro médico ni prestaciones laborales. En ocasiones, al momento de ser empleados, firman unos papeles como si estuvieran recibiendo un salario, pero de hecho no lo reciben. Otras veces tienen derecho a ciertas prestaciones, aunque de manera discrecional; pero nadie tiene la menor garantía de permanecer en su trabajo, ya que pueden ser despedidos en cualquier momento sin previo aviso y quiera enterados, pero que sirven justamente para proteger al sector patronal (Bouzas, 2007).

10 A través de la organización en cuestión, el STRACC, se han devuelto algunos primeros resultados de la investigación bajo la forma de engargolados $y$ un libro colectivo en el cual un capitulo está dedicado al estudio de sus redes de apoyo en el ámbito laboral. Véase al respecto Giglia (2014).

territarios 35

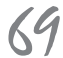


sin ningún tipo de obstáculo para el patrón. Para que esto sea posible es común que, al momento de ser empleados, sean obligados a firmar unas cuantas hojas en blanco, que servirán al patrón para redactar su renuncia ya firmada en el momento en que decida deshacerse de ellos. En suma, su condición se explica también a partir de la violación recurrente de la ley laboral que propicia el establecimiento de relaciones informales de trabajo y la ausencia de una defensa sindical real. En los últimos años las empresas tienden a contratar cada vez más a perfiles de trabajadores que de por sí se prestan para ser más flexibles y vulnerables, es el caso de los jóvenes y especialmente de las mujeres madres solteras. Estas últimas, son consideradas más responsables que los hombres y son las que más fácilmente pueden ser sometidas a las exigencias del trabajo, es decir, las que pueden chantajearse con facilidad. Los jóvenes porque se considera que están más dispuestos a aceptar las condiciones de trabajo actuales por no haber conocido mejores condiciones en el pasado, o por ver el empleo como una ocupación provisional, en vista de encontrar algún otro más conveniente. Los hombres mayores por no poder acceder a otros trabajos, lo que los hace más controlables y sumisos. Estos perfiles responden de manera fehaciente a la definición de precariado propuesta por Standing (2013) y Wacquant (2007).

En el ambiente de trabajo se gestan diversos tipos de redes para sortear la precariedad y la falta de salario y para hacer frente a las circunstancias propias de esta condición laboral. Por ejemplo, si un cliente abandona la estación de gasolina sin pagar o si hay alguna falta de dinero al final de un turno, todos los trabajadores cooperan para que la merma económica no recaiga únicamente sobre una persona. Esas redes de apoyo, que involucran amigos, compañeros de trabajo y familiares, las encontramos desde los inicios de la relación laboral, ya que en muchos casos la inserción en el trabajo es el resultado de contactos familiares y también, aunque menos frecuente, de relaciones de amistad. Es muy común que un nuevo trabajador llegue a una gasolinera porque ha sido recomendado por un pariente o un amigo que ya está laborando allí. Este le informa que hay un puesto vacante y lo presenta al gerente o al jefe de turno. En general, los gerentes de las gasolineras valoran positivamente estos lazos a la hora de contratar a un despachador, pues los consideran una suerte de garantía acerca del buen comportamiento y de la honestidad del trabajador en cuestión. Se trata, como hemos visto, de un trabajo en el cual se necesitan altas dosis de confianza recíproca, el ingrediente ya individuado por Larissa Lomnitz (1975) en su estudio sobre las redes de los marginados. La confianza es requerida especialmente por la circulación de grandes cantidades de dinero en el lugar de trabajo, de allí que los familiares sean bienvenidos por el mayor compromiso reciproco que implica el vínculo familiar. El reclutamiento por la vía del parentesco da como resultado la formación de familias de gasolineros, en las que tres o más personas, de distintas generaciones o de la misma, se desempeñan en el mismo oficio, transmi- 
tido de una generación a otra, ya sea en la misma gasolinera o en varias estaciones. Esto aumenta el conocimiento del oficio y el capital de saberes y relaciones de los despachadores, así como su visión de conjunto acerca de los cambios ocurridos en los últimos años ${ }^{11}$.

En la dimensión socio espacial, relativa a la manera de organizar la vida cotidiana y la experiencia de la metrópoli, la importancia de las redes no es menor, sino que resulta más bien indispensable. Las redes propias del ámbito familiar y vecinal permiten la articulación entre el ámbito doméstico y el ámbito laboral, organizando la movilidad del lugar de residencia al lugar de trabajo. En ausencia de servicios públicos locales como guarderías o escuelas de tiempo prolongado, las redes familiares resultan imprescindibles para sobrellevar los turnos y el ritmo de trabajo, especialmente cuando se tiene que enfrentar una movilidad cotidiana en la metrópoli que implica largos trayectos entre la casa y el lugar de trabajo y cuando se tiene que atender a hijos en edad escolar, familiares enfermos o muy ancianos que necesitan de asistencia. Cuando se puede contar con el apoyo de parientes que no viven en la misma casa, los trayectos cotidianos suelen incluir hacer una parada en la casa de estos familiares ya sea para ir a dejar o a recoger a los hijos pequeños. Así cuando es posible, la ubicación del lugar de residencia toma en cuenta de manera estratégica las conexiones y la facilidad de acceso al lugar de residencia de los familiares a los cuales se puede pedir ayuda para el cuidado de los hijos. En otros casos, estos apoyos se obtienen de manera más estable mediante la cohabitación con parientes ancianos o que no tienen su propio núcleo familiar.

Para ilustrar en concreto algunos de estos temas, y especialmente la problemática de la dimensión socio-espacial de la marginalidad, expongo a continuación dos casos de trabajadores, un hombre y una mujer, que se encuentran situados en posiciones opuestas con respecto a la ubicación en la metrópoli y las distancia del lugar de trabajo. El primer caso es el de un hombre que vive cerca de la gasolinera donde trabaja en un contexto urbano céntrico y en una casa en la cual no tiene que pagar renta. El otro caso se refiere a una mujer que vive a dos horas de distancia de su lugar de trabajo en una colonia popular consolidada, en una vivienda en renta. Como veremos, anticipando algo de las conclusiones, en ambos casos, pese a sus diferencias, la importancia de las redes de apoyo es crucial para salir adelante. Los entrevistados serán denominados aquí con los seudónimos de Eduardo e Irene.

Eduardo tiene un poco más de treinta años, está casado, tiene una hija en edad escolar y trabaja en una gasolinera cerca de Insurgentes sur a quince minutos en bicicleta de su casa. Vive en uno de los pueblos conurbados de la delegación Coyoacán, en una vivienda que pertenece a su mamá con la cual también cohabita y de la cual es en parte responsable económicamente. Su mamá es conocida en el barrio por haber estado involucrada como representante vecinal. Él la apoya económicamente desde hace varios años, especialmente cuando se
${ }^{11}$ Sin embargo, la experiencia adquirida no es considerada por los patrones como algo bueno, sino como un sinónimo de competencias que el trabajador puede usar en beneficio propio $y$ para dañar al patrón. Los despachadores con experiencia pueden ser menos controlables en cuanto son más conscientes de sus derechos y de los secretos del oficio. Es preferible uno que no sepa casi nada y que deba ser instruido por la empresa que uno competente, en la medida en que su experiencia es interpretada por el gerente no solo como una babilidad para trabajar bien, sino también para aprovecharse de la situación. Es lo que se define como un trabajador "amañado".

territarias 35

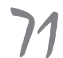


separó de su padre y empezó a tener más problemas con los gastos de la casa. Actualmente su mamá trabaja en una empresa privada donde gana 600 pesos a la semana, dice que lo hace para no estar en la casa y para que le den su jubilación. Además tiene sus vales (bonos) para gastar, y los gastos de la casa los paga Eduardo. De él dependen su esposa que está estudiando una carrera en administración de empresas, y su hija que frecuenta la escuela primaria. La casa de su mamá está en un terreno que es también de propiedad de algunos tíos y se encuentra actualmente en un litigio con otros vecinos. Este es un asunto que lo preocupa ya que podría perjudicar su permanencia en ese lugar, pero no ha podido aclarar los términos exactos de la situación, la cual por otra parte es muy común en México en este tipo de vivienda que ha sido construida de manera irregular. Parece ser que los dueños de este terreno murieron sin hacer testamento, por lo cual actualmente es muy complicado poder adjudicarse su propiedad de manera plena, aunque por el momento no hay riesgo de que tengan que abandonarla. Eduardo ha trabajado desde la edad de los once años como ayudante de albañil, como botarga, malabarista y dibujante en una oficina. El hecho de vivir en una zona céntrica lo ha favorecido ya que ha podido encontrar en las calles mismas cercanas a su barrio una oportunidad sencilla y relativamente redituable de ganarse la vida. Cuando iba en la escuela técnica preparatoria, estuvo un año sin poder frecuentar porque había reprobado tres materias y tenía que pasar los exámenes. En ese año se dedicó a ser malabarista en compañía de un amigo. Se ponían los fines de semanas en algunos semáforos de vialidades céntricas y muy frecuentadas, hacían unas horas de malabares y luego se iban al centro de la ciudad, donde casi siempre gastaban ese dinero en unas cervezas. En estas ocupaciones, todas igualmente eventuales, informales y precarias, su remuneración era por mucho superior al salario mínimo legalmente establecido. Empezó a trabajar en la gasolinera situada en un lugar muy concurrido, a tres cuadras de su casa, gracias a un familiar que ya trabajaba allí como jefe de una isla (hilera compuesta por dos máquinas despachadoras situadas debajo del mismo techo). Su mamá estaba preocupada de que se quedara un año sin ir a la escuela y habló con ese pariente el cual a su vez habló con el gerente de la gasolinera y a la semana siguiente Eduardo pudo entrar a trabajar un par de días por semana (para tener el tiempo de estudiar para sus exámenes), pese a ser menor de edad y sin la necesidad de presentar ningún documento. Allí poco a poco se hizo de un lugar en la gasolinera abriéndose espacio en la jerarquía. Después de casi diez años tuvo que dejarla por un conflicto que se generó a raíz de la muerte del dueño y del cambio de propietario. Gracias a otros amigos gasolineros logró conseguir un puesto en otra gasolinera igualmente céntrica, donde está desde hace cuatro años. Es un poco más lejos, pero va en bicicleta y no le pesa para nada. En el año en que estuvo esperando terminar la preparatoria, trabajó también como dibujante en un estudio de arquitectos. Le pagaban apenas 
500 o 600 pesos a la semana y tenía que llevarse el trabajo a la casa para terminar lo que le habían asignado para el día siguiente. Cuando empezó a trabajar en la gasolinera dejó el estudio de arquitectos porque ya no le convenía.

Ha terminado la escuela preparatoria, pero ahora es indeciso en cuanto a volver a estudiar una carrera, pese a que su mamá y su suegra quisieran que lo intentara. Considera que el trabajo de gasolinero "le ha dado para mucho", ha podido viajar con su esposa a diversos lugares, menciona entre ellos las últimas vacaciones a la playa, y considera que se ha divertido mucho gracias a los recursos procedentes de las propinas. Aun así, no se ve toda la vida trabajando de propinero, pero no ubica aún otra ocupación que de verdad le interese, posiblemente será el diseño de interiores. Visitando su página de una conocida red social es fácil darse cuenta de que su vida es bastante alegre, con frecuentes reuniones con sus amigos a comer o a bailar y salidas con su familia fuera de la ciudad de México, tipo día de campo, vacaciones en la playa en lugares cercanos a la ciudad de México como es el caso de Acapulco, salidas con su hija a distintos lugares céntricos, ya sea como tarea de la escuela o por simple diversión y paseo familiar. En suma, el caso de Eduardo, que no es infrecuente en este medio, nos muestra que una remuneración precaria pero no tan escasa como sería el salario mínimo, acompañada de una red familiar estable y protectora y de una ubicación céntrica en la metrópoli se traducen en una condición de vida que es definida como satisfactoria y hasta placentera. En la biografía de Eduardo vemos actuar a las redes de apoyo de manera estratégica en los momentos difíciles, cuando necesita encontrar la manera de salir adelante.

El caso de Irene presenta en cambio una situación más difícil en la cual el contexto espacial de residencia incrementa las dificultades propias de las otras esferas de la vida que de por sí ya son problemáticas. En primer lugar se trata de una mujer que es jefa de hogar ya que está separada, mantiene dos hijos en edad escolar. En segundo lugar tiene que rentar la vivienda en donde vive, se trata de dos cuartos con baño en una colonia de autoconstrucción situada en el municipio conurbado de Netzahualcóyotl, en el oriente del área metropolitana, a dos horas de distancia del lugar de trabajo, una gasolinera ubicada sobre el anillo Periférico. Más de una vez menciona la presión que siente al tener que proveer a sus hijos en todas sus necesidades: recargas para los celulares, Internet, libros, zapatos, transporte, materiales para la escuela, etc. No quiere dejar de trabajar como gasolinera porque necesita darles dinero todos los días a sus hijos para sus necesidades y para eso las propinas que recibe de manera cotidiana sirven bastante bien, ciertamente mejor que un sueldo quincenal miserable en otro tipo de empleo, como cuando trabajaba como auxiliar administrativo en una oficina, con "un sueldo nefasto", con lo cual "empezaba la quincena pidiendo prestado". En el predio donde renta su vivienda cohabita con otras familias y esto le implica ciertos problemas en la manera de utilizar y territarias 35 73 
cuidar los espacios comunes, especialmente el patio. Normalmente Irene se dedica en la mañana a las labores domésticas y en la tarde-noche al trabajo. Manifiesta que últimamente por el tiempo que gasta en el trayecto al trabajo, ha dejado de cocinar y de limpiar su casa como hacía antes. Esto le ha provocado algunos conflictos leves con sus vecinas con las cuales comparte el patio. Ellas son muy dadas a lavarlo, mientras que ella se preocupa más bien por ahorrar el agua. Deja que el quehacer de la casa lo hagan sus hijos o que se compren algo afuera para cenar, ya que ella llega a veces después de la medianoche de su trabajo. Pese a este horario postmeridiano, dice que "afortunadamente todo bien", es decir que no ha padecido ningún asalto últimamente en los medios de transponte públicos, algo que se ha vuelto cada vez más usual, sobre todo en el transporte que va del centro hacia las periferias. Esto hace que muchas personas adopten medidas ad hoc, como por ejemplo tener dos celulares, uno mejor y otro más económico, listo para ser sacrificado en el caso de un asalto en el medio de transporte, en donde los ladrones buscan justamente los celulares y otras pertenencias de todos los pasajeros.

En lo que se refiere a la crianza de sus hijos, su ejemplo es su mamá, que siempre ha sido muy ordenada y bastante severa. Su madre es bastante anciana y no tiene casa propia. Esto hace que viva por temporadas en las casas de sus hijos, una solución que es común en México. Cuando está en casa con Irene le ayuda bastante con las tareas del hogar y con los hijos. En cambio Irene se preocupa de que no le falten sus medicinas. Gracias a un amigo que conoció en una fiesta, desde hace pocas semanas ha empezado a trabajar en una estación de gasolina donde le prometieron que tendrá el seguro social. Sin embargo esta estación está a dos horas de distancia de su casa y esto le complica mucho la vida. Por una parte necesita el seguro sobre todo para las necesidades de salud de su madre, pero por otra parte siente que el tiempo que gasta en el transporte público es demasiado. En la relación con sus hijos adolescentes se hace más evidente lo difícil de su situación de madre trabajadora, a dos hora de distancia de casa y además en el turno de tarde-noche. La relación con ellos, como en el caso de otras madres obligadas a pasar la mayoría del tiempo lejos de casa, se desarrolla por la vía de la comunicación telefónica, mediante la cual se controlan paso a paso los desplazamientos y se acompañan a los hijos en su cotidianidad, pero a la distancia. Para resolver sus emergencias económicas Irene suele pedir prestado a sus familiares, especialmente a sus hermanos y a una hermana de su madre quienes gozan de una condición económica mejor que la suya. Gracias a estas personas puede enfrentar los gastos extra de sus hijos, sabiendo además de que se trata de una ayuda que no necesita recompensar en el corto plazo, porque son relaciones en las cuales predomina la confianza. Entre los otros recursos de los cuales echa mano para salir adelante se encuentran el esforzarse para sacar el máximo posible de su trabajo, mediante lo que define como una "buena actitud", ya 
que considera que de esto depende el que haya buenas propinas, especialmente cuando se establece una red de clientes asiduos con los cuales se puede platicar en términos amigables. Otro recurso para salir adelante consiste en no permitirse faltar al trabajo, ni siquiera cuando está enferma, con base en la creencia de que las "enfermedades son psicosomáticas". También le es de mucha ayuda el confiar en Dios y mantener una actitud positiva ante todo tipo de circunstancia. Su lema de vida es: "todo positivo". No puede permitirse ver las cosas de otra manera, porque se derrumbaría el frágil equilibrio que rige su vida y especialmente la relación con sus hijos que dependen de ella. Aun así, sabe que puede contar con sus familiares y con algunos de sus compañeros de trabajo en un momento difícil o en el caso de una necesidad económica. En el balance sobre su situación, la distancia del lugar de trabajo, la imposibilidad de dejar a sus hijos con algún familiar o una de sus vecinas con las cuales no se lleva bien, aumentan considerablemente su cansancio y su ansiedad, volviéndola más vulnerable. Reconoce que el trabajo que tiene ahora le conviene, pero la distancia que tiene que recorrer es tal que está pensando en renunciar.

\section{De regreso a las teorías, a manera de conclusión}

Las diferencias en la condición de Eduardo e Irene son evidentes y repercuten en como hablan de su situación y como se definen a sí mismos. Eduardo se declara satisfecho y hasta se atreve a visualizar algún plan para el futuro, mientras que Irene admite todas y cada una de sus desventajas y se muestra concentrada sobre todo en su presente, lidiando con el frágil equilibrio entre los recursos, los pagos, las distancia y las personas que dependen de ella. Está claro que la distancia del lugar de trabajo modifica en mucho sus condiciones generales de vida, además de la propiedad de la vivienda de la cual disponen. Aun con estas diferencias, las redes sociales son en ambos casos una parte esencial e indispensable del capital con el cual enfrentan la precariedad de su condición, que asumen como un hecho estable y no transitorio, una situación estructural y no eventual. La condición de precariedad en el trabajo se corresponde y se superpone a la definición de marginalidad de Lomnitz y a la de marginalidad avanzada de Wacquant. Pero estos dos últimos conceptos evocan una condición más general de acumulación de desventajas y escasez de medios de integración que van mucho más allá de la precariedad laboral.

En lo que se refiere a su condición general en la actualidad, estos trabajadores precarios no se asemejan a aquellos que hace treinta años se definían como marginales, y esto por diversa razones. En primer lugar, no siempre son trabajadores escasamente calificados, como los marginados estudiados por Lomnitz, ni se trata de trabajadores imposibilitados para hacer labores que requieran de una mayor calificación profesional. Varios de los gasolineros entrevistados han trabajado en labores de tipo secretarial o intelectual, como empleados 
en oficinas con sueldo fijos y han experimentado la insuficiencia de sueldo y la sobreexplotación de esa condición. Su situación refleja la de un precariado que, según la definición de Standing, concierne hoy en día a casi todos los niveles y sectores de la economía, no solo los poco calificados. Su condición de precariedad y marginalidad es funcional al mantenimiento de salarios ínfimos y sirve para que se imponga un tipo de condiciones laborales en las que la falta de derechos mínimos es asumida como un hecho normal. Esta condición de marginalidad no está afuera, sino adentro del sistema, y como bien lo apunta Wacquant, al denominarla como marginalidad avanza$d a$, su presencia está destinada a prolongarse en el futuro y no a extinguirse. En tercer lugar, la condición de los propineros parece diferenciarse de lo sostenido por este autor al definir la marginalidad avanzada como una condición de desvinculación de ciertos lazos locales, especialmente cuando subraya la pérdida del lugar y de un hinterland protector en el cual los marginados puedan encontrar refugio y apoyo en los momentos más críticos. Sin descartar que situaciones atomizadas de este tipo existan, como ha sido evidenciado por otros autores (De la Rocha, 2001), considero, sin embargo, que no es este el caso de los gasolineros objeto de este artículo, los cuales en cambios aún se sostienen en redes familiares, laborales y locales suficientemente confiables como para considerarlas un apoyo insustituible para sobrellevar la precariedad y sobre todo las dificultades que se derivan de la distancia del lugar de trabajo y de la falta de protec- ción en caso de un gasto imprevisto que trasciende la manutención cotidiana. En ese sentido, es de suma importancia el tema de los ajustes entre localización del lugar de residencia y lugar de trabajo mediante las redes de apoyo familiar.

En suma, las redes sociales parecen ser todavía un capital importante para estos trabajadores precarios, y este dato no deja de suscitar un cierto asombro. Otra sorpresa que nos reserva el acercamiento a los gasolineros consiste en remarcar que pese a estar sometidos a condiciones de trabajo híper-flexibles, viven mejor que los trabajadores con sueldos y horarios fijos e inclusive con niveles de escolaridad más altos. Ellos mismo se consideran en una mejor condición con respecto quienes reciben un pago quincenal en un régimen de empleo asalariado. Expresan esta convicción con base en su experiencia de vida, recordando los periodos en que estuvieron trabajando con un sueldo fijo que resultó totalmente insuficiente en comparación con las propinas que reciben todos los días. Paradójicamente, dentro de la incertidumbre que permea su relación laboral, las propinas cotidianas parecen ser el elemento más predecible, capaz incluso de brindarle cierta estabilidad a su vida diaria, aunque su monto puede variar. Para que haya un día sin propinas, debe haber sucedido una desgracia o un imprevisto mayúsculo. De otra forma, si hay trabajo habrá el dinero de las propinas. La ventaja de ser propineros consiste por lo tanto en tener un ingreso diario para nada despreciable, sobre el cual se puede contar, que permite sobrellevar los gastos 
cotidianos de la comida, de la escuela y el transporte de los hijos. Ganar 200 o 300 pesos al día con las propinas es más de tres veces el salario mínimo establecido por ley (70 pesos diarios), que se aplica en México para los trabajadores poco calificados (no solo obreros, sino también vendedores, vigilantes, afanadores, ayudantes de albañiles, etc.). Muchos de los gasolineros entrevistados consideran además que les resulta más fácil y más redituable administrar sus recursos con base en un ingreso diario, y no quincenal o mensual. Con lo cual asumen como natural un modo de vida basado en un horizonte de muy corto plazo, del día a día.

Esta situación es un resultado de la aniquilación del trabajo frente al capital que caracteriza actualmente la coyuntura económica en México, un país en el cual no se han dado históricamente las mismas condiciones de afiliación a los sistemas de protección social característicos de los países europeos (Castel, 1995), y en el cual por lo tanto no existe una memoria colectiva ampliamente compartida acerca de una época de seguridades en el empleo. Esto contribuye a explicar la naturalidad con la cual los propineros enfrentan su condición de precariedad, y como se ajustan a un modo de vida basado en el día a día, aceptando el desamparo en aspectos como la seguridad social o el seguro médico como parte de los costos inevitables de tener recursos cotidianamente. La visión sobre su situación laboral y vivencial está marcada por una actitud de "al mal tiempo buena cara" es decir que ante las necesidades, las carencias y las casi nulas esperanzas de ver mejorar su situación, escogen conscientemente no darse el lujo del desánimo, porque además están conscientes de que su situación es mejor respecto a la que viven otros. "No queda más que luchar y vivir de las ilusiones", dice un entrevistado. En suma, la existencia es una lucha diaria, que se gana en buena medida gracias al apoyo de los demás, tanto en la organización de la vida cotidiana como en la solución de circunstancias imprevistas. La complejidad de las peripecias cotidianas entre la casa, el trabajo y la escuela de los hijos, los vuelve muy sensibles a los acomodos cotidianos relativos a la gestión de estos desplazamientos, vinculada a la conexión temporo-espacial entre lugar de residencia y lugar de trabajo. Cuando llegan a un ajuste satisfactorio tienden a mantenerlo aun cuando esto signifique soportar un tiempo de traslado más largo o tener que renunciar a otras actividades.

Tanto Lomnitz como Standing y Wacquant tienen presente la importancia de los vínculos sociales para la supervivencia de los trabajadores precarios. Sin embargo, mientras Lomnitz hace cuarenta años subrayaba con razón la eficacia de las redes de apoyo, los análisis más recientes conducidos por Standing y Wacquant tienden más bien a poner en duda la persistencia de un tejido social que pueda sostener los marginados actuales en las grandes ciudades y evidencian en cambio el peso de la acumulación de desventajas que se genera para aquellos que viven en lugares alejados y desprovistos de servicios básicos y desconectados del resto del tejido urbano. Esta desigualdad es territarias 35 77 
evidente en los dos casos presentados aquí en los cuales el segundo, Irene, sufre de esa multiplicación de condiciones negativas relacionadas con el hecho de vivir en un lugar situado a más de dos horas de distancia de su lugar de trabajo. Mientras el caso de Eduardo muestra como una localización ventajosa se acompaña con oportunidades de supervivencia y con una visión más optimista de sus posibilidades y su condición. En general, la posibilidad de aminorar y/o sobrellevar la marginalidad y la precariedad puede cambiar en relación con un conjunto de factores concadenados, que no son únicamente laborales, sino también socioespaciales. Se trata de factores que resultan inseparables cuando se observa cómo actúan en la práctica, ya que la eficacia y la utilidad de las redes informales de apoyo tienen mucho que ver con la ubicación de los sujetos en el espacio metropolitano, con su tiempo de permanencia y arraigo en el espacio local, con sus estrategias de movilidad en la metrópoli, a su vez vinculadas al mantenimiento de las redes. De allí la necesidad de un enfoque holístico para el estudio de la marginalidad y la precariedad, para tomar en cuenta el conjunto de las interacciones entre todos sus aspectos, no solo los laborales, sino también los que se refieren a la inserción en redes de relaciones de apoyo y a la relación con la vivienda y su contexto urbano. territarias 35

\section{Referencias}

Alba, C., Lins Ribeiro, G. \& Mathews, G. (2015). La globalización desde abajo. La otra economía mundial. Ciudad de México: Fondo de Cultura Económica.

Bauman, Z. (2000). Trabajo, consumismo y nuevos pobres. Ciudad de México: Paidos.

Bensusán, G. (2000). El modelo mexicano de regulación laboral. Ciudad de México: UAM-FLACSO-Fundación Ebert Stiftung-Plaza y Valdez.

Bensusán, G. (2009). Estándares laborales y calidad de los empleos en América Latina. Perfiles Latinoamericanos, 34, 14-49.

Bourdieu, P. (1999). La miseria del mundo, Buenos Aires, Fondo de Cultura Económica.

Bouzas Ortiz, J. A. (2010). Perspectivas del trabajo en México. México: UNAM.

Castel, R. (1995). Les metamorphoses de la cuestión social. Une cronique du salariat. Paris: Gallimard.

Castel, R. (2007). «Au-delà du salariat ou en deçà de l'emploi ? L'institutionnalisation du précariat ?». En S. Paugam (Dir.), Repenser la solidarité : l'apport des sciences sociales (pp. 416-433). Paris: PUF (Coll. « Le lien social»).

Duhau, E. y Giglia, A. (2008). Las reglas del desorden. Habitar la metrópoli. Ciudad de México: Siglo XXI.

Castel, R., Kessler, G., Merklen, D. \& Murard, N. (2013). Individuación, precariedad, inseguridad: ¿Desinstitucionalización del presente? Buenos Aires: Paidós.

Ángela Giglia 
De la Rocha, M. G. (2001). From the resources of poverty to the poverty of resources? The erosion of a survival model. Latin American Perspectives, 28(4), 72-100.

De la Rocha, M. G., Perlman, J., Safa, H., Jelin, E., Roberts, B. R. \& Ward, P. M. (2004). From the marginality of the 1960s to the" New Poverty" of Today: A LARR Research Forum. Latin American Research Review, 39(1), 183-203.

Kaztman, R. (2001). Seducidos y abandonados. Revista de la CEPAL, 75, 171-189.

Lewis, O. (1970). Antropología de la pobreza. México: Fondo de Cultura Económica.

Giglia, A. (2014). Trabajo precario y redes de solidaridad. El caso de los despachadores de gasolinas de la ciudad de México, En A. Giglia \& A. Miranda. Precariedad urbana y lazos sociales: una mirada comparativa entre México e Italia (pp. 109136). Ciudad de México: Ediciones Juan Pablos - UAM Ixtapalapa.

Giglia, A. (2012). El habitar y la cultura. Perspectivas teóricas y de investigación. Barcelona: Anthropos-UAM.

INEGI (2016). Instituto nacional de estadística, Geografía e Informática. Recuperado el 17 de febrero de 2016, de http:// www.inegi.org.mx/est/contenidos/ proyectos/cn/informal/.

Lomnitz, L. (1975). Cómo sobreviven los marginados. México: Siglo XXI.

Mora Salas, M. (2010). Ajuste y empleo. La precarización del trabajo asalariado en la era de la globalización. México: El Colegio de México.
Monnet, J., Giglia, A. \& Capron, G. (2007) Ambulantage et services à la mobilité: les carrefours commerciaux à Mexico. Street Trade and Mobility Services: the Crossroads in Mexico City. Cybergeo, 1, 1-50.

Nun, J. (1969). Superpoblación relativa ejercito industrial de reserva y masa marginal. Revista latinoamericana de sociología (2), 180-225.

Nun, J. (2001). Marginalidad y exclusión social. Buenos Aires: Fondo de Cultura Económica.

O'Donnell, G. A. \& Tokman, V. E. (1999). Pobreza y desigualdad en América Latina. Buenos Aires: Paidós.

Paugam, S. (2007). Las formas elementales de la pobreza. Madrid: Alianza.

Peña Díaz, Y., \& Castillo Robledo, G. (2014). El Salario Fantasma de un Trabajo Real: El caso de los empacadores de la tercera edad en la Comercial Mexicana. Trabajo terminal de la licenciatura en antropología, Departamento de Antropología, UAM Iztapalapa, asesora Ángela Giglia.

Quijano, A. (1988). La formación de un universo marginal en las ciudades de América Latina. En M. Bassols et al. (Coords.), Antología de sociología urbana (pp. 340- 365). Ciudad de México Ciudad de México: UNAM. (Edición original de 1971 en la revista Espace et Sociétés, nun 3, julio 1971).

Saraví, G. (Coord.). (2006). De la pobreza a la exclusión. Continuidades y rupturas de la cuestión social en América Latina Buenos Aires: Prometeo. territarios 35 79 
Standing, G. (2013). Precariado. Una nueva clase social. Barcelona: Ediciones Pasado y Presente.

Wacquant, L. (2007). Los condenados de la ciudad. Gueto periferias y estado. Buenos Aires: Siglo XXI. 